\title{
Human resources for health in Peru: recent trends (2007-2013) in the labour market for physicians, nurses and midwives
}

\author{
M. Michelle Jimenez ${ }^{1 *}$, Anthony L. Bui ${ }^{2}$, Eduardo Mantilla ${ }^{3}$ and J. Jaime Miranda ${ }^{1}$
}

\begin{abstract}
Background: Most analyses of gaps in human resources for health $(\mathrm{HRH})$ do not consider training and the transition of graduates into the labour market. This study aims to explore the labour market for Peru's recent medical, nursing, and midwifery graduates as well as their transition into employment in the Ministry of Health's $(\mathrm{MOH})$ system.

Methods: Data from four different datasets, covering 2007-2013, was used to characterize the patterns of recently trained physicians, nurses, midwives, and postgraduate-trained physicians that enter employment in the $\mathrm{MOH}$ system, and scenario analyses were used to describe how this rate of entry needs to adapt in order to fill current HRH shortages.

Results: HRH graduates have been increasing from 2007 to 2011, but the proportions that enter employment in the $\mathrm{MOH}$ system 2 years later range from 8 to $45 \%$ and less than 10\% of newly trained medical specialists. Scenario analyses indicate that the gap for physicians and nurses will be met in 2027 and 2024, respectively, while midwives in 2017. However, if the number of HRH graduates entering the MOH system doubles, these gaps could be filled as early as 2020 for physicians and 2019 for nurses. In this latter scenario, the MOH system would still only utilize 56\% of newly qualified physicians, $74 \%$ of nurses, and $66 \%$ of midwives available in the labour market.

Conclusion: At 2013 training rates, Peru has the number of physicians, nurses, and midwives it needs to address $\mathrm{HRH}$ shortages and meet estimated HRH gaps in the national $\mathrm{MOH}$ system during the next decade. However, a significant number of newly qualified health professionals do not work for the $\mathrm{MOH}$ system within 2 years of graduation. These analyses highlight the importance of building adequate incentive structures to improve the entry and retention of $\mathrm{HRH}$ into the public sector.
\end{abstract}

Keywords: Human resources for health, Labour market, Peru

\section{Background}

Changes in demography, epidemiology, and disability burden patterns create increasing pressure on healthcare systems and the roles of healthcare professionals [1]. In order to achieve universal health coverage, countries need to train, incorporate, and retain enough healthcare professionals into their health systems to meet the needs of the whole population. Peru, a country facing a double burden of communicable and non-communicable diseases [2], still

\footnotetext{
* Correspondence: jimenezmichelle@yahoo.ca

${ }^{1}$ CRONICAS Centre of Excellence in Chronic Diseases, Cayetano Heredia

University, Av. Armendáriz 497, Miraflores, Lima 18, Peru

Full list of author information is available at the end of the article
}

faces gaps in access to healthcare related in part to difficulties in the recruitment and retention of health workers in rural and remote regions [3].

The World Health Organization has defined the minimum threshold to provide essential maternal and child healthcare services as 23 physicians, nurses, and midwives per 10000 population [4], as a lower density of healthcare professionals has been associated with increased maternal, infant, and under-five mortality rates [5]. While Peru met the overall threshold for human resources for health (HRH) density at 29.6 in 2015 , there remains a distribution problem, with a high concentration of HRH in larger metropolitan areas such as Lima, Callao, and Arequipa [6]. However, 
the classical analysis of shortages of HRH based on their density per population has its shortcomings in that it does not consider the labour market perspective [7], such as the supply end (training of graduates), nor the transition of labour into and outside of the system, including migration. Peru has seen a rise in medical schools, 33 in 2010 compared to 3 in 1960, and changes to healthcare workers contracts in 2008-with a shift to more temporary ones, making it harder to secure permanent positions [8]. Exploring the labour market for Peru's recent medical, nursing, and midwifery graduates can provide better understanding of the patterns of Peru's HRH shortage.

Benefiting from access to primary data sources, this study has three objectives: (1) to quantify how many recently trained physicians, nurses, and midwives enter the national health system of the Ministry of Health $(\mathrm{MOH})$; (2) to describe how the rate of entry into Peru's health sector should adapt in order to fill the HRH gap in physicians, nurses, and midwives at the primary care level, [NB: this gap has been defined by the $\mathrm{MOH}$ [9] as a difference between needs and availability, the former calculated by estimating population catchment areas and demand for medical services listed in the Essential Health Insurance Plan, and the latter as provided by the National Observatory for HRH]; and (3) to quantify how many postgraduate-trained physicians in specialties deemed as priority by the $\mathrm{MOH}$ (anaesthesiology, family and community medicine, general surgery, gynaecology and obstetrics, internal medicine, and paediatrics) enter the MOH's public health system.

\section{Context}

Healthcare in Peru is provided by the MOH, ESSALUD, Armed Forces and National Police, and the private sector. The publicly funded $\mathrm{MOH}$ system cares for approximately $60 \%$ of the population, while ESSALUD, a contribution- based social security system, covers approximately $30 \%$ [8, 10]. Figure 1 presents this study's conceptual framework showing the labour market for HRH in Peru, focusing on the MOH's system only. After training, HRH interested in pursuing employment or postgraduate training within the MOH's system must first spend 1 year completing the Urban Rural Marginal Internship Program (SERUMS), working at the primary care level in rural or urbanmarginal areas. After completing SERUMS, professionals may continue to work for the $\mathrm{MOH}$ system or join other healthcare sectors and may apply to various universities offering training positions within hospitals for postgraduate specialist training.

In terms of the offer of training for health professionals, there was a significant increase in the number of private universities created during the 1990s in Peru. Thus, the offer of university-level training has increased significantly [8]. At the same time, the number of State-funded universities and their ability to train professionals has not expanded significantly in the last decades.

\section{Methods \\ Data sources}

This study used four databases: (a) graduate numbers from university training programmes for physicians, nurses, and midwives for 2007-2011 were obtained from the National Assembly of Deaneries (detailed analyses on these data have been published previously [11]); (b) applicants, entrants, and graduates of SERUMS for 2007-2013; (c) MOH's National Observatory for $\mathrm{HRH}$ including data on individual employment status and titles for 2007, 2009, 2010, and 2012, both provided by the Ministry of Health's HRH Management and Development Directorate; and (d) entrants into postgraduate clinical specialties deemed as priority by the $\mathrm{MOH}$ for

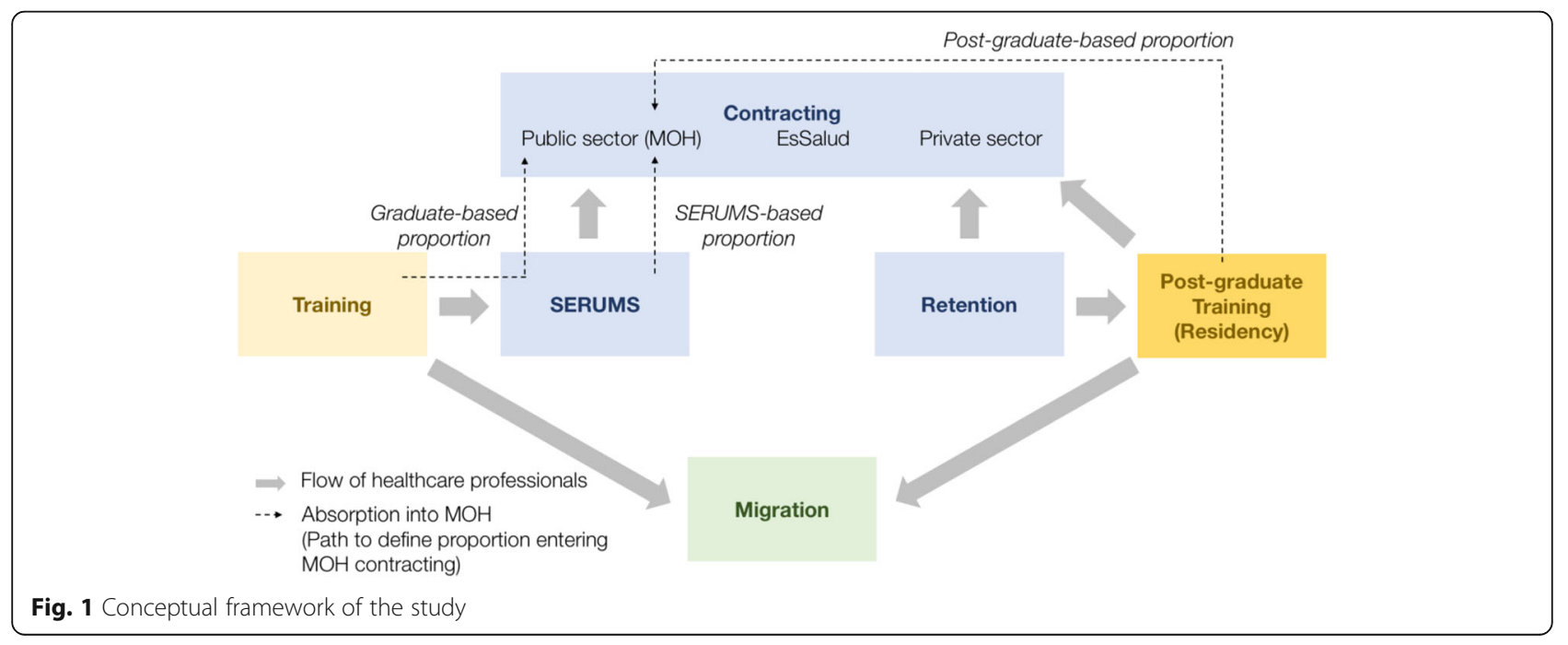


2009-2010 provided by the National Committee for Medical Residencies. This study excludes ESSALUD, Armed Forces and National Police, and the private sector due to lack of data on number and type of $\mathrm{HRH}$ working in these sectors.

\section{Analysis \\ Graduates entering the national health system}

The numbers of university graduates from 2007 to 2011 was compared to the numbers of SERUMS healthcare workers in the immediate subsequent year, i.e. 2008 number of SERUMS was compared to the number of 2007 graduates, reflecting five cohorts of graduates, to calculate the proportion of graduates that begin SERUMS immediately after completing university. The transition of SERUMS graduates to employment status within the $\mathrm{MOH}$ system was analysed by matching individuals' names in the SERUMS database covering 2007-2012 with the National Observatory of HRH database as of September 2013. The matching was done by staff at the MOH's National Observatory of $\mathrm{HRH}$, and the study team received an anonymised dataset. For each of the five annual cohorts, a SERUMS-based proportion was calculated as the fraction of SERUMS healthcare workers that enter the $\mathrm{MOH}$ system in the following year, as well as an overall graduate-based proportion of those entering the $\mathrm{MOH}$ system, dividing the number of new $\mathrm{MOH}$ healthcare workers by the total number of graduates 2 years prior.

\section{Scenarios for closing the HRH gaps}

Gaps in $\mathrm{HRH}$ and supply of new $\mathrm{MOH}$ healthcare workers were projected from 2013 through 2050 by combining $\mathrm{MOH}$-estimated gaps in $\mathrm{HRH}$, projections of population growth derived from the National Institute of Statistics and Informatics, and the number of healthcare professionals that would graduate in the coming years, by applying the average ratio of graduates to students in the period 2007-2011 to the number of students entering university in 2008-2011 and assuming this ratio remained constant. Other assumptions were that starting in 2016, the number of professionals taking up SERUMS positions would stay constant and be equal to the projections for that year. Even though an increase in the number of new professionals could be expected, there are also a number that are lost every year; thus, it was assumed that the number of additional entries into SERUMS would balance the number of those who quit SERUMS. It was also assumed that the proportion of professionals who keep working in the $\mathrm{MOH}$ system remained constant. Analysis of scenarios was then varied by SERUMS-based proportions. Tables of projected gaps have been published elsewhere [12].

\section{Postgraduate physicians entering the national health system}

Physicians pursuing postgraduate clinical specialization do so as part of a national residency programme in hospitals across the Peruvian health sector, with the majority available at $\mathrm{MOH}$ and ESSALUD hospitals and thus financed mainly by the Government. Data on physicians entering postgraduate training in $\mathrm{MOH}$ hospitals during 2009-2010 was compared to the number of medical specialists entering the MOH system in 2012 and 2013 to assess whether the numbers of potential new specialists available in Peru are reflected in the number of specialists entering the public sector, once their training is finished. A postgraduatebased proportion was calculated by dividing the number of specialists hired by the MOH system in 2012 and 2013 to the number of entrants into postgraduate clinical training for MOH-priority specializations in 2009 and 2010.

\section{Results}

\section{Flow of healthcare professional graduates}

Figure 2 shows the number of graduates from 2007 to 2011, the number of SERUM positions that were filled in the immediate year after (2008-2012), and those individuals who, after completing their SERUMS, were employed by the $\mathrm{MOH}$ system in the following year (2009-2013). Overall, both the number of graduates and the number of SERUMS healthcare professionals across physicians, nurses, and midwives has increased throughout this period, due in part to an $\mathrm{MOH}$ strategy to increase the availability of SERUMS positions to staff rural and remote health centres [9]. In turn, following graduation and SERUMS service, while the number of physicians entering the $\mathrm{MOH}$ system has slightly increased from 2007 to 2011, the number of nurses and midwives slightly decreased during the same time period.

In terms of the proportion of graduates who enter SERUMS, all physicians tend to do so, compared to an average of $62 \%$ for nurses and $85 \%$ for midwives over the time period. The arrows displayed on the figure depict the proportion of graduated professionals who become employed by the $\mathrm{MOH}$ system 2 years later, indicating the entry from the total pool of newly trained HRH available. However, it is the proportion of professionals that have completed their SERUMS and then become employed that shows the actual entry rate, given that a complete SERUMS is a prerequisite for employment in the MOH system. Using proportions of SERUMS-completed HRH that enter the MOH system (data not shown), the average uptake of employment over the time period was $28 \%$ for physicians, 37\% for nurses, and 33\% for midwives.

\section{Closing the HRH gap-a scenario analysis}

Table 1 presents nine different scenarios in which the $\mathrm{MOH}$ system can fill its gaps of physicians, nurses, and 


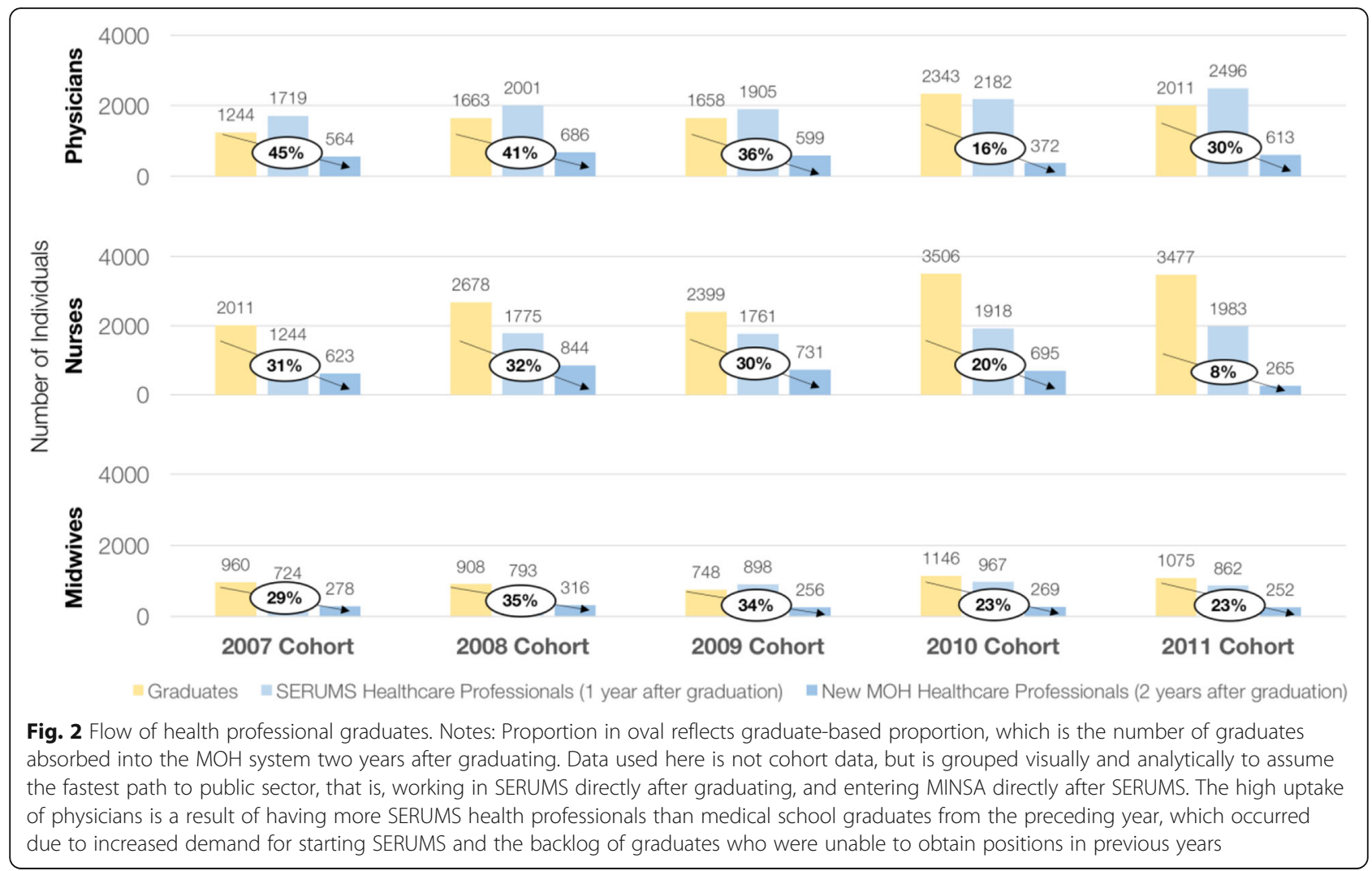

midwives. Proportions of SERUMS professionals who enter the $\mathrm{MOH}$ as new hires are provided, as well as the year that the gap for a HRH role would be met assuming these proportions stayed constant. Under the current rate of entry into $\mathrm{MOH}$ employment, the gap in physicians would be met in 2027, nurses in 2024, and midwives in 2017. By doubling the SERUMS-based proportions, gaps would be filled as early as 2020 and 2019 for physicians and nurses, respectively. In this latter scenario, of the total of newly qualified HRH available in the Peruvian labour market, the $\mathrm{MOH}$ system would still utilize only $56 \%$ of physicians,
$74 \%$ of nurses, and $66 \%$ of midwives. By decreasing its SERUMS-based proportion by $20 \%$ (scenario 8 ), the gaps would be filled several years later, 2030 for physicians, 2027 for nurses, and 2018 for midwives.

\section{Entry of medical specialists into the MOH system}

Table 2 shows the number of entrants into medical residency specialties in 2009 and 2010 and compares these to the number of specialists hired by the $\mathrm{MOH}$ system in 2012 and 2013, when these entrants would have completed their residency training. Specialists that completed

Table 1 Closing the gap

\begin{tabular}{|c|c|c|c|c|c|c|c|c|c|c|}
\hline & & $\begin{array}{l}\text { Current } \\
\text { situation } \\
0 \%{ }^{\mathrm{b}}\end{array}$ & $\begin{array}{l}\text { Scenario } 1 \\
+10 \%^{\mathrm{b}}\end{array}$ & $\begin{array}{l}\text { Scenario } 2 \\
+20 \%^{b}\end{array}$ & $\begin{array}{l}\text { Scenario } 3 \\
+30 \%{ }^{\mathrm{b}}\end{array}$ & $\begin{array}{l}\text { Scenario } 4 \\
+40 \%{ }^{\mathrm{b}}\end{array}$ & $\begin{array}{l}\text { Scenario } 5 \\
+50 \%{ }^{\mathrm{b}}\end{array}$ & $\begin{array}{l}\text { Scenario 6+ } \\
100 \%{ }^{b}\end{array}$ & $\begin{array}{l}\text { Scenario } 7 \\
-10 \%{ }^{b}\end{array}$ & $\begin{array}{l}\text { Scenario } 8 \\
-20 \%^{b}\end{array}$ \\
\hline \multirow[t]{2}{*}{ Physicians } & Proportion $^{a}$ & 0.28 & 0.31 & 0.34 & 0.36 & 0.39 & 0.42 & 0.56 & 0.25 & 0.22 \\
\hline & $\begin{array}{l}\text { Year gap is } \\
\text { met }\end{array}$ & 2027 & 2025 & 2024 & 2024 & 2023 & 2022 & 2020 & 2028 & 2030 \\
\hline \multirow[t]{2}{*}{ Nurses } & Proportion ${ }^{a}$ & 0.37 & 0.41 & 0.44 & 0.48 & 0.52 & 0.56 & 0.74 & 0.33 & 0.30 \\
\hline & $\begin{array}{l}\text { Year gap is } \\
\text { met }\end{array}$ & 2024 & 2023 & 2023 & 2022 & 2021 & 2021 & 2019 & 2026 & 2027 \\
\hline \multirow[t]{2}{*}{ Midwives } & Proportion $^{a}$ & 0.33 & 0.36 & 0.40 & 0.44 & 0.46 & 0.50 & 0.66 & 0.30 & 0.26 \\
\hline & $\begin{array}{l}\text { Year gap is } \\
\text { met }\end{array}$ & 2017 & 2017 & 2017 & 2017 & 2016 & 2016 & 2016 & 2018 & 2018 \\
\hline
\end{tabular}

a Proportion listed is SERUMS-based proportion, i.e. percentage of SERUMS health professionals that enter as new MOH hires

${ }^{b}$ Percent change of SERUMS-based proportion from current situation's proportion, which is the average SERUMS-based proportion from 2007 to 2011 
Table 2 Absorption of 2009-2010 medical residents in the public sector, 2012-2013

\begin{tabular}{|c|c|c|c|c|c|c|c|}
\hline & Admis & to resic & & Recen & of resid & $\mathrm{MOH}$ & \\
\hline & 2009 & 2010 & Total & 2012 & 2013 & Total & $\begin{array}{l}\text { based } \\
\text { proportion of } \\
\mathrm{MOH} \\
\text { entrants (\%) }\end{array}$ \\
\hline General surgery & 65 & 78 & 143 & 20 & 8 & 28 & 19.6 \\
\hline Paediatrics & 88 & 118 & 206 & 22 & 15 & 37 & 18.0 \\
\hline Anaesthesiology & 72 & 87 & 159 & 23 & 5 & 28 & 17.6 \\
\hline Internal medicine & 59 & 78 & 137 & 11 & 5 & 16 & 11.7 \\
\hline Gynaecology and obstetrics & 87 & 117 & 204 & 16 & 4 & 20 & 9.8 \\
\hline Family and community medicine & 33 & 42 & 75 & 0 & 1 & 1 & 1.3 \\
\hline Overall total & 924 & 1156 & 2080 & 148 & 58 & 206 & 9.9 \\
\hline
\end{tabular}

their training by 2012 and 2013 would be eligible for $\mathrm{MOH}$ employment. Results show that only $9.9 \%$ of the total specialists were hired by the $\mathrm{MOH}$ system in those years. General surgeons, paediatricians, and anaesthesiologists joined the $\mathrm{MOH}$ system in higher numbers, but only one family and community medicine specialist joined the MOH system in 2013.

\section{Discussion}

This study reports on a particular point in the cycle of $\mathrm{HRH}$ planning: the transition from training to employment in the national health system, in a country where this sector provides care for $60 \%$ of the population. Results from this analysis of primary data show that at 2013 training rates, Peru has the number of physicians, nurses, and midwives it needs to meet the estimated $\mathrm{HRH}$ gap in the national $\mathrm{MOH}$ system during the next decade. This is explained by the number of $\mathrm{HRH}$ graduates, which has been increasing from 2007 to 2011 due to the additional offer of training provided by private universities [11]. Yet, our analyses show that not only is availability of new graduates important but that current entry rates of $\mathrm{HRH}$ into employment by the $\mathrm{MOH}$ system may hinder meeting such targets. The proportion of HRH graduates entering the $\mathrm{MOH}$ system 2 years later ranges from 8 to $45 \%$ during the period of this study, showing that a significant number of qualified professionals do not enrol in the $\mathrm{MOH}$ system workforce in the immediate year after completing their SERUMS. Scenario analyses indicate that if 2013 absorption rates are held, the gap for physicians and nurses will not be met until 2027 and 2024, respectively, while the gap for midwives will likely be met by 2017 . Furthermore, less than one in five newly trained $\mathrm{MOH}$-priority medical specialists enrol in the $\mathrm{MOH}$ system workforce, suggesting that there are some major barriers to entry immediately after SERUMS and after completion of postgraduate clinical training.
Shortages in HRH have been reported in Peru indicating substantial deficiencies in the total number of available healthcare professionals and medical specialists $[8$, 13]. Using a labour market framework, the shortage of healthcare professionals in Peru may be explained by the low proportions of healthcare professionals entering the $\mathrm{MOH}$ system from SERUMS or from postgraduate clinical training shown in this study, high rates of outmigration [14], and low rates of retention rather than merely a limited supply in training of professionals [11].

The differences in the proportion of graduates who enter SERUMS (nearly 100\% of physicians vs. $62 \%$ of nurses and $85 \%$ of midwives over the time period) in the immediate year after graduation could indicate that nurses and midwives may have other options of immediate employment in the private sector or the social security system that do not require being posted in a remote and rural area and may even offer longer-term opportunities than the $\mathrm{MOH}$.

The average proportion of SERUMS healthcare professionals entering the $\mathrm{MOH}$ system has been consistently low, $28 \%$ of physicians, $38 \%$ of nurses, and $33 \%$ of midwives. To increase the number of healthcare professionals in the $\mathrm{MOH}$ system, strategies to raise the proportion of SERUMS-completed healthcare professionals and graduated medical specialists entering the $\mathrm{MOH}$ system need to be explored. In 2009, the Peruvian government instituted a strategy to increase the number of SERUMS positions at rural and remote outposts available to physicians [8], and while this indeed increased the number of SERUMS physicians, as seen in Fig. 2, these results show that it did not ultimately translate into more healthcare professionals remaining within the $\mathrm{MOH}$ system immediately after completing their SERUMS.

Entering employment in the $\mathrm{MOH}$ system from SERUMS is clearly not linear, but further investigation is needed to understand the specific barriers such as those on the supply side (e.g. lack of $\mathrm{MOH}$ system positions, mismatch between skills [11]) or the demand side (e.g. 
salary, work hours, prestige, professional development opportunities). Miranda et al. [15] and Huicho et al. [16] found that in Ayacucho, Peru, physicians were five times more likely, and nurses and midwives 14 times, to choose an urban-based job over a rural one. Incentives that professionals preferred included salary increases and bonus points to gain entry into postgraduate training programmes. For example, Mayta-Tristán et al. [17] proposed that SERUMS should be voluntary and not time-limited, offer academic incentives for further training after 3 years of service, and ensure basic workplace protection for the HRH. These proposals are modelled on the successful Rural Practitioner Program in Chile, a programme with a near $100 \%$ retention rate [18]. Nevertheless, recent reviews of recruitment and retention strategies for primary care physicians have found weak evidence $[19,20]$ except for some limited effectiveness of undergraduate and postgraduate placements in underserved areas and selective recruitment of medical students (i.e. those from rural areas) [19]. Similarly, the low proportions of medical specialists entering the $\mathrm{MOH}$ system after postgraduate clinical training not only further exacerbate the workforce shortage but indicate a significant loss of training investment. Although some of these losses can be explained by migration [14], further research is needed to evaluate the proportion of medical specialists who enter the $\mathrm{MOH}$ system in future years and explore possible barriers of entry, including availability of employment offers and their geographical distribution.

In addition to the low proportions of SERUMScompleted healthcare professionals and medical specialists entering the $\mathrm{MOH}$ system, the workforce shortage is compounded by mismatched training competency. Peru has been able to meet its demand for training in healthcare professions, with $70 \%$ of graduates attending private universities, yet a massive disconnect remains between the primary care-level competencies developed in universities and those desired by the $\mathrm{MOH}$ [11]. This mismatch continues for medical specialists in primary care with only one joining the MOH system in 2013 and low demand for postgraduate training positions within the $\mathrm{MOH}$ system (251 available in 2013 and only 143 taken up) [6].

These findings can be relevant to health systems in other countries, where quantity of HRH may not be critical but other constraints and barriers, fiscal or otherwise, exist [21]. For example, Peru has sufficient number of medical schools, 33 vs. 20 in Australia and 25 in England [9, 22, 23 , and students to meet the physician gap. Yet, these results indicate that there are several points postgraduation (nurses and midwives) and post-SERUMS (all professionals) in which the system fails to attract and/or retain the professionals required to counteract HRH shortages. Countries that are investing in the development of their $\mathrm{HRH}$ should consider also investing in understanding health labour market trends [7], such as the rates of entry to employment at different points in a healthcare professional's trajectory and determining the barriers to entering the public national health system. Building adequate incentive structures to improve the entry and retention of $\mathrm{HRH}$ into the public sector will require an evaluation of the value provided by already committed resources, including their cost-effectiveness [22] to ensure the best use of limited resources.

This study provides an assessment of the transition of healthcare professionals from university training, through SERUMS, and entry into the $\mathrm{MOH}$ system. It moves beyond merely quantifying HRH and signalling gaps in density to explore what happens to HRH within the local labour market and incorporates the complexity of various transition points. The main strength of this study included the ability to track individuals over time to assess if they ultimately become employed by the $\mathrm{MOH}$ system in the immediate year after completing their SERUMS, providing a robust exploration of trends over the time period. It makes use of primary data, rather than models or theoretical assumptions, and as such could be considered innovative. The focus of the study has international significance in relation to the market for physicians, nurses, and midwives in Peru, particularly in attracting new graduates into employment in the Ministry of Health's (MOH) system. Nevertheless, this study has limitations. Data on HRH in this study accounts for those working for the $\mathrm{MOH}$ system, excluding those working for other sectors, such as ESSALUD and the private sector. Yet, because the $\mathrm{MOH}$ system covers the majority of the population, these findings still show evidence of matters causing the gap in healthcare professionals. Furthermore, the MOH's databases shared with the authors did not include information on salaries, and no primary data sources on levels of HRH unemployment and migration existed to the knowledge of the authors. Projections were based on average rates for a period of 5 years. The analysis looked at the transition of HRH from graduation, to SERUMS, and then employment in the MOH system in the immediate years after but did not consider that professionals may join further on. However, it can be assumed that those employed by the $\mathrm{MOH}$ system are not employed by ESSALUD at the same time (as this is not allowed by the Government), although they might have a dual practice in the private sector. In spite of its limitations, the scenario projections included in this study may prove useful to policymakers in Peru and other countries in the same stage of development, to persuade them to use concurrent and synergic strategies to address gaps in $\mathrm{HRH}$.

\section{Conclusion}

Peru faces significant HRH shortages, and an analysis of its labour market shows a complex pattern with high availability of newly graduated $\mathrm{HRH}$, and yet low 
entry into employment structures of the $\mathrm{MOH}$ system. These analyses provide evidence of the importance of understanding health labour market trends as a basis to build incentive structures for $\mathrm{HRH}$ to join the public national health system, not only in Peru but also in other countries investing in the development of their $\mathrm{HRH}$.

\section{Acknowledgements \\ Not applicable.}

\section{Funding}

This study was funded by the Japan-World Bank PHRD Partnership Grant for Universal Health Coverage (UHC) as part of the MoU between the Peruvian Ministry of Health and the World Bank (contract no. 7168680). MMJ and EM were supported by the study's grant during its duration. JJM has been supported by Alliance for Health Policy and Systems Research (HQHSR1206660); Consejo Nacional de Ciencia; Tecnología e Innovación Tecnológica (CONCYTEC); DFID/MRC/Wellcome Global Health Trials (MR/ M007405/1); Fogarty International Center (R21TW009982); Grand Challenges Canada (0335-04); International Development Research Center Canada (106887, 108167); Inter-American Institute for Global Change Research (IA CRN3036); National Heart, Lung and Blood Institute (5U01HL114180, HHSN268200900028C); National Institute of Mental Health (1U19MH098780); Swiss National Science Foundation (40P740-160366); Universidad Peruana Cayetano Heredia; and Wellcome Trust (GR074833MA, WT093541AIA 103994/Z/14/Z). ALB was funded under the UCLA Blum Center on Poverty and Health in Latin America.

The funders had no role in the design of the study, data collection, analysis, interpretation, or writing up of the findings. MMJ and EM had full access to all the data, and MMJ and JJM had final responsibility for the decision to submit for publication.

\section{Availability of data and materials}

The datasets used and/or analysed during the current study are available from the corresponding author on reasonable request.

\section{Authors' contributions}

MMJ and JJM conceived the study and were responsible for its implementation and completion. EM carried out the data analysis and ALB produced the figures and tables. MMJ and ALB wrote the manuscript. All authors had final approval of the submitted and published versions.

Ethics approval and consent to participate

This study used anonymized datasets and thus did not require ethics approval.

\section{Consent for publication}

Not applicable.

\section{Competing interests}

The authors declare that they have no competing interests.

\section{Publisher's Note}

Springer Nature remains neutral with regard to jurisdictional claims in published maps and institutional affiliations.

\section{Author details}

'CRONICAS Centre of Excellence in Chronic Diseases, Cayetano Heredia University, Av. Armendáriz 497, Miraflores, Lima 18, Peru. ²David Geffen School of Medicine at UCLA, Los Angeles, United States of America. ${ }^{3}$ ESAN University, Lima, Peru.
Received: 3 March 2017 Accepted: 13 September 2017

Published online: 21 September 2017

\section{References}

1. Crisp N, Chen L. Global supply of health professionals. N Engl J Med. 2014; 370:2247-8

2. Huynen MM, Vollebregt $L$, Martens $P$, Benavides BM. The epidemiologic transition in Peru. Rev Panam Salud Publica. 2005;17:51-9.

3. Reich MR, Harris J, Ikegami N, Maeda A, Cashin C, Araujo EC, Takemi K, Evans TG. Moving towards universal health coverage: lessons from 11 country studies. Lancet. 2016:387:811-6.

4. World Health Organization (WHO). Achieving the health-related MDGs. It takes a workforce! http://www.who.int/hrh/workforce_mdgs/en/ (accessed 23/09/2016)

5. Anand S, Bärnighausen T. Human resources and health outcomes: crosscountry econometric study. Lancet. 2004;364:1603-9.

6. Ministry of Health (MINSA). Información de recursos humanos en salud. Dirección General de Gestión del Desarrollo de Recursos Humanos, Observatorio de Recursos Humanos en Salud. Lima: MINSA; 2015. p. 57.

7. McPake B, Maeda A, Araújo EC, Lemiere C, El Maghraby A, Cometto G. Why do health labour market forces matter? Bull World Health Organ. 2013;91:841-6.

8. Ministry of Health (MINSA). Recursos humanos en salud al 2011: Evidencias para la toma de decisiones. Dirección General de Gestión del Desarrollo de Recursos Humanos, Observatorio de Recursos Humanos en Salud del Perú: MINSA, Lima; 2011. p. 114.

9. Ministry of Health (MINSA). Guía Técnica para la Metodología de Cálculo de las Brechas de Recursos Humanos en Salud para los Servicios Asistenciales del Primer Nivel de Atención. Dirección General de Gestión del Desarrollo de Recursos Humanos, Dirección de Gestión del Trabajo en Salud. Lima: MINSA; 2014. p. 116

10. Alcalde-Rabanal JE, Lazo-González O, Nigenda G. The health system of Peru. Salud Publica Mex. 2011;53(Suppl 2):s243-54. Review. Spanish

11. Jiménez MM, Mantilla E, Huayanay-Espinoza CA, Gil K, García H, Miranda JJ. Demand for training and availability of health science professionals in Peru. Rev Peru Med Exp Salud Publica. 2015:32:41-50. Spanish

12. Jimenez MM, Mantilla E, Huayanay C, Mego M, Vermeersch CMJ. Analysis of the health care labor market in Peru. Health, nutrition and population (HNP) discussion paper. Washington, DC: World Bank Group; 2015. p. 86.

13. Zevallos L, Pastor R, Moscoso B. Supply and demand of medical specialists in the health facilities of the Ministry of Health: national, regional and by type of specialty gaps. Rev Peru Med Exp Salud Pública. 2011;28:177-85. Spanish.

14. Pan-American Health Organization (PAHO). Migración calificada en salud, impacto financiero, reconocimiento de títulos: retos y perspectiva en los países de la región Andina. Lima: PAHO; 2013. p. 210.

15. Miranda JJ, Diez-Canseco F, Lema C, Lescano AG, Lagarde M, Blaauw D, Huicho L. Stated preferences of doctors for choosing a job in rural areas of Peru: a discrete choice experiment. PLoS One. 2012;7:e50567.

16. Huicho L, Miranda JJ, Diez-Canseco F, Lema C, Lescano AG, et al. Job preferences of nurses and midwives for taking up a rural job in Peru: a discrete choice experiment. PLoS One. 2012;7:e50315.

17. Mayta-Tristán P; Poterico JA, Galán-Rodas E, Raa-Ortiz D. [Mandatory requirement of social health service in Peru: discriminatory and unconstitutional] Rev Peru Med Exp Salud Publica 2014;31:781-787. Spanish.

18. Peña S, Ramirez J, Becerra C, Carabantes J, Arteaga O. The Chilean Rural Practitioner Programme: a multidimensional strategy to attract and retain doctors in rural areas. Bull World Health Organ. 2010;88:371-8.

19. Verma P, Ford JA, Stuart A, Howe A, Everington S, Steel N. A systematic review of strategies to recruit and retain primary care doctors. BMC Health Serv Res. 2016:16:126.

20. Grobler L, Marais BJ, Mabunda S. Interventions for increasing the proportion of health professionals practising in rural and other underserved areas. Cochrane Database Syst Rev. 2015;30:CD005314.

21. Mandeville KL, Lagarde M, Hanson K, Mills A. Human resources for health: time to move out of crisis mode. Lancet. 2016;388:220-2.

22. Medical Deans of Australia and New Zealand: http://www.medicaldeans.org au/statistics/annualtables/. Accessed 23 Sept 2016.

23. The Health and Education National Strategic Exchange. Review of medical and dental school intakes in England. England: Department of Health \& Higher Education Funding Council for England (HEFCE); 2012. 